\title{
Climate variability and drought modulate the role of structural refuges for arthropods: a global experiment
}

Gustavo Romero ${ }^{1}$, Thiago Gonçalves-Souza ${ }^{2}$, Tomas Roslin ${ }^{3}$, Robert Marquis ${ }^{4}$, Nicholas Marino ${ }^{5}$, Vojtech Novotny ${ }^{6}$, Tatiana Cornelissen ${ }^{7}$, Jerome Orivel ${ }^{8}$, Shen Sui $^{9}$, Gustavo Aires $^{10}$, Reuber Antoniazzi ${ }^{11}$, Wesley Dattilo ${ }^{12}$, Crasso Breviglieri ${ }^{2}$, Annika Busse ${ }^{13}$, Heloise Gibb $^{14}$, Thiago Izzo ${ }^{15}$, Tomas Kadlec ${ }^{16}$, Victoria Kemp ${ }^{17}$, Monica Kersch-Becker ${ }^{18}$, Michal Knapp ${ }^{19}$, Pavel Kratina ${ }^{20}$, Rebecca Luke ${ }^{21}$, Stefan Majnarić ${ }^{22}$, Robin Maritz ${ }^{23}$, Paulo Martins ${ }^{24}$, Esayas Mendesil ${ }^{25}$, Jaroslav Michalko ${ }^{26}$, Anna Mrazova ${ }^{27}$, Samuel Novais $^{28}$, Cássio Pereira ${ }^{7}$, Mirela Perić ${ }^{22}$, Jana Petermann ${ }^{29}$, Servio Ribeiro ${ }^{30}$, Katerina Sam $^{31}$, M. Kurtis Trzcinski ${ }^{32}$, Camila Vieira ${ }^{2}$, Natalie Westwood ${ }^{33}$, Maria Bernaschini ${ }^{34}$, Valentina Carvajal ${ }^{35}$, Ezequiel González ${ }^{36}$, Mariana Jausoro ${ }^{37}$, Stanis Kaensin ${ }^{9}$, Fabiola Ospina $^{35}$, Jacob Cristóbal-Pérez ${ }^{38}$, Mauricio Quesada ${ }^{39}$, Pierre Rogy ${ }^{32}$, Diane Srivastava ${ }^{40}$, Scarlett Szpryngiel ${ }^{41}$, Ayco Tack ${ }^{42}$, Tiit Teder ${ }^{43}$, Martin Videla ${ }^{34}$, Mari-Liis Viljur ${ }^{43}$, and Julia Koricheva ${ }^{44}$

${ }^{1}$ State University of Campinas (UNICAMP)

${ }^{2}$ UNICAMP

${ }^{3}$ Swedish University of Agricultural Sciences

${ }^{4}$ University of Missouri-St. Louis

${ }^{5}$ Universidade Federal do Rio de Janeiro

${ }^{6}$ Institute of Entomology, Czech Academy of Sciences

${ }^{7}$ UFMG

${ }^{8}$ CNRS, UMR Ecofog

${ }^{9}$ New Guinea Binatang Research Center

${ }^{10}$ Federal Rural University of Pernambuco

${ }^{11}$ Stephen F Austin State University

${ }^{12}$ Instituto de Ecología AC

${ }^{13}$ Bavarian Forest National Park

${ }^{14}$ La Trobe University

${ }^{15} \mathrm{UFMT}$

${ }^{16}$ Czech University of Life Sciences Prague Faculty of Environmental Sciences

${ }^{17}$ Queen Mary, University of London

${ }^{18}$ The University of Alabama System

${ }^{19}$ Czech University of Life Sciences Prague

${ }^{20}$ Queen Mary University of London

${ }^{21}$ Royal Holloway University of London

${ }^{22}$ University of Zagreb

${ }^{23}$ University of the Western Cape

${ }^{24}$ Universidade Federal Rural de Pernambuco

${ }^{25}$ Jimma University 
${ }^{26}$ Slovak University of Agriculture in Nitra

${ }^{27}$ Biology Centre Czech Academy of Sciences

${ }^{28}$ Universidad Nacional Autónoma de México Escuela Nacional de Estudios Superiores

Unidad Morelia

${ }^{29}$ Universitat Salzburg

${ }^{30}$ Universidade Federal de Ouro Preto

${ }^{31}$ University of South Bohemia and Institute of Entomology

${ }^{32}$ The University of British Columbia

${ }^{33}$ The University of British Columbia Faculty of Science

${ }^{34}$ Instituto Multidisciplinario de Biología Vegetal

${ }^{35}$ Universidad de Caldas

${ }^{36}$ University of Koblenz Landau Faculty 5 of Education

${ }^{37}$ Universidad Nacional de Chilecito

${ }^{38}$ Instituto de Investigaciones en Ecosistemas y Sustentabilidad, Universidad Nacional Autónoma de México.

${ }^{39}$ Universidad Nacional Autonoma de Mexico

${ }^{40}$ University of British Columbia

${ }^{41}$ Swedish Museum of Natural History

${ }^{42}$ Stockholm University

${ }^{43}$ University of Tartu

${ }^{44}$ University of London

January 29, 2021

\begin{abstract}
Current climate change is disrupting biotic interactions and eroding biodiversity worldwide. However, species sensitive to drought, high temperatures and climate variability might persist in microclimatic refuges, such as leaf shelters built by arthropods. We conducted a distributed experiment across an 11,790 km latitudinal gradient to explore how the importance of leaf shelters for terrestrial arthropods changes with latitude, elevation and underlying climate. Our analyses revealed leaf shelters to be key facilitative elements for the diversity of arthropods. Predator diversity and overall biomass within shelters increased with local drought and temperature variability, regardless of latitude and elevation. In contrast, shelter usage by herbivores increased with abundance of predators on those same plants and in wetter climates. Projected increase in climatic variability and drought in certain geographic regions is therefore likely to enhance the importance of biotic refuges, especially for predators, in mitigating the impact of climate change on species persistence.
\end{abstract}

\title{
INTRODUCTION
}

Climate warming, extreme precipitation events and temperature variability are all intensifying at unprecedented rates (IPCC Climate Change, 2014; Donat et al. , 2016; Bathiany et al ., 2018). Such changes cause species-environment mismatches, and have already led to shifts in the geographic ranges and elevational or vertical distributions of species as they track their climatic niche (Vázquezet al ., 2017; Essl et al ., 2019; Trisos et al ., 2020). As other means to avoid adverse conditions, terrestrial species may seek microclimatic refuges (Scheffers et al ., 2014; Suggittet al ., 2018) and even manipulate their own microclimate (Pincebourde and Casas, 2019). Microclimatic refuges provided by a variety of habitat structural components including plant architectural complexity, tree bark, downed woody debris, leaf litter, and leaf shelters - reduce the exposure of their inhabitants to climate variability and extremes (Scheffers et al ., 2014; Suggittet al ., 2018; Pincebourde and Casas, 2019; Pinsky et al ., 2019). Such refuges can be particularly important 
to ectotherms (Pinskyet al ., 2019), such as arthropods. Ectotherms depend on external energy to thermoregulate and are amongst the taxa most threatened by global change (García-Robledo et al ., 2016; Warren et al.,2018; Wagner, 2020; Wagner et al ., 2021). The availability of these refuges, and their impact on insect use, may be one factor mitigating the various negative climatic factors leading to insect decline.

Protection against harsh environmental conditions is typically provided by ecosystem engineers, which are organisms that modify their habitats by creating physical structures that can be used as structural refuges by other organisms (Jones et al. Hastings et al ., 2007; Romeroet al ., 2015). In terrestrial ecosystems, bark beetles and stem borers make stem and trunk galleries, gallers manipulate plant physiology to produce galls, and various arthropods (e.g., caterpillars, aphids, mites and thrips) build leaf shelters, such as leaf rolls and ties, thus providing refuge to many other plant-dwelling organisms (Wanget al., 2012; Vieira and Romero, 2013; Cornelissen et al ., 2015; Priest et al ., 2021). The role of leaf-rolling engineers as biodiversity amplifiers can be even stronger in dry seasons, and extend to the whole plant, thus influencing arthropod assemblages at temporal and microspatial scales (Vieira and Romero, 2013). After such shelters are abandoned by their creators, they become available for other arthropods for a long period of time (Vieira and Romero, 2013). Similar to many other biotic interactions, which are stronger at lower latitudes (Schemske et al., 2009), the facilitative effects of vertebrate and invertebrate ecosystem engineers seem particularly pronounced in the wet tropics, but also in arid regions (Romero et al ., 2015). Therefore, these latitudinal, regional (Romero et al ., 2015) and temporal patterns (Vieira and Romero, 2013) suggest that climatic conditions may be a common driver underlying such facilitative interactions.

Large-scale patterns in climatic signatures have been recently investigated using standardized replicated experiments, which can differentiate the direct effects of climate from the indirect effects of latitude or elevation on biotic interactions (LaManna et al ., 2017; Roslin et al ., 2017; Romero et al ., 2018). Most of these macroecological studies have focused on antagonistic interactions, such as predation and competition (LaManna et al ., 2017; Roslinet al ., 2017; Romero et al ., 2018). Although the importance of facilitative interactions among organisms is expected to increase under stressful conditions (He et al ., 2013; Romeroet al ., 2015), no empirical studies to date have examined the impacts of current climate and climate variability, or predicted the impacts of future climates, on facilitative interactions at global scale.

Here, we test the effects of current and future climatic scenarios on facilitation mechanisms provided by leaf-rolling ecosystem engineers. We compare how current and projected climate affects the usage of leaf rolls by terrestrial arthropods, and how shelter usage is affected by body size and trophic position. We hypothesize that abundance, species richness and biomass of arthropods within leaf rolls will increase with increasing climate variability and drought. We also expect that species' responses to climate will vary with their trophic position and body size, both of which are known to influence the metabolic requirements of ectotherms (Daufresne et al., 2009) and their capacity to dissipate heat (Rubalcaba et al., 2019). Competition at higher trophic levels (predators) selects for larger body size. Larger-bodied organisms typically require more favourable climatic conditions than their prey (Petchey et al., 1999; Voigt et al., 2003; Brose et al., 2012). Therefore, we expect larger predators to be dominant in refuges especially in arid and climatically variable regions (Fig. 1). Finally, with continuing climate change, we expect current climatic dependencies to reflect future changes in geographic patterns of refuge use by arthropods.

To test the above predictions, we conducted a global, coordinated experiment at 52 sites across an 11,790 km latitudinal gradient (from $45.8^{\circ} \mathrm{S}$ to $60.2^{\circ} \mathrm{N}$, Fig. 1) and elevation spanning from 5 to $2900 \mathrm{~m}$ above sea level. To measure the beneficial effects of leaf rolls, we recorded abundance and diversity of arthropods colonizing manually rolled and control (unrolled) leaves, and calculated the standardized mean difference (Hedges' d) between arthropod abundance, species richness, biomass and body size in rolled and control leaves for each site. To test how climate influences shelter colonization, we investigated the effects of different categories of moderators (predictor variables) on the Hedges' d effect size, including both geographic distance (absolute latitude, elevation) and direct measures of climate (temperature and precipitation). Finally, we provide geographical interpretations of climate change scenarios on the patterns of refuge use and predict future changes in refuge use by projecting effect sizes to future (2070) climatic conditions at the study locations. 


\section{MATERIAL AND METHODS}

\section{Study sites}

We performed a geographically-coordinated experiment simulating the presence of ecosystem-engineering structures built by leaf-rolling caterpillars on plants. The experiment was replicated in 2017-2019 in 52 sites across an $11,790 \mathrm{~km}$ latitudinal gradient $\left(45.8^{\circ} \mathrm{S}\right.$ to $\left.60.2^{\circ} \mathrm{N}\right)$ and elevation spanning from 5 to $2900 \mathrm{~m}$ above sea level, comprising diverse types of biomes, including tropical and temperate forests, xeric shrubland (caatingas), savannas etc. We considered our sites spatially independent, as $94 \%$ of them were at least 500 $\mathrm{km}$ apart from each other. A detailed description of the sites, including environment and plant features, is provided in Table S1.

\section{Global experiment and arthropod samples}

Experiments at all 52 sites were conducted following a standardized protocol. Each experiment followed a randomized block design; for each site, we randomly chose 10 to 20 paired trees, shrubs or herbs (blocks). Paired plants were at least $2 \mathrm{~m}$ apart from each other. Each block was at least $6 \mathrm{~m}$ apart from each other. In most sites, the experiment was conducted using a single native plant species, typically the most common species locally. However, in some tropical forests, due to the high species diversity and low relative density, we used different plant species among blocks, but the plants within each pair always belonged to the same species. We only used broadleaf native plant species that did not bear any apparent type of indirect defence (e.g., domatia, extra-floral nectaries, glandular trichomes) (Romero and Koricheva, 2011).

One plant in each pair was randomly chosen as a control whereas the second plant was used for the leaf-rolling (shelter addition) treatment. On each plant, we selected 5-10 fully expanded leaves without apparent damage. Prior to the experiment, any arthropods present were removed by hand from leaves. Then, the leaves on the treatment plant were manually rolled from the adaxial to the abaxial surface transversally to the leaf axis to form a cylinder of roughly $0.6 \mathrm{~cm}$ in diameter (Fig. S1) to mimic shelters built by caterpillars from at least 17 moth and butterfly families, including Hesperiidae, Nymphalidae, Gelechiidae, Oecophoridae, Lasiocampidae, Pyralidae, Gracillariidae, Tortricidae, Geometridae, Erebidae (Fitzgerald et al ., 1991; Fukui, 2001; Lill and Marquis, 2007). The rolls were secured with a metal hairpin (see Fig. S1 and Vieira and Romero, 2013). The control plant of the pair had 5-10 unrolled leaves marked with a metal hairpin. Rolled and control leaves were exposed for 10 days in the field. This was deemed sufficient as previous bioassays showed that leaf shelters can be colonized very quickly (within 24 hours) (Vieira and Romero, 2013). Maximum width of both control and rolled leaves was measured as an estimate of leaf size.

After 10 days of the experiment, we collected rolled and control leaves, and stored them grouped per replicate and treatment in small zip-lock plastic bags. The leaves were either frozen for later sorting or immediately sorted to collect the invertebrates. We collected all the invertebrates visible to the naked eye (except mites) and stored them in ethanol. We identified the invertebrates to the lowest taxonomic level possible and classified them into morphospecies and feeding guild (i.e., predator, parasitoid, herbivore, detritivore, omnivore). Individual body size (dry body mass) was estimated from the dry mass (dried at $70^{\circ} \mathrm{C}$ for $24 \mathrm{~h}$ ) or by measuring total body length and then calculating the dry mass through published taxon-specific allometric equations (Hódar, 1996). Four dependent variables were used for analyses: arthropod abundance, species richness, biomass and mean body size. Arthropod biomass represented the sum of all individual body masses. All variables were weighted by the number of sampled leaves per plant.

\section{Climate, topography and productivity data}

We extracted different sets of current climate data for two purposes: (i) to test the prediction that climate variability and drought would influence the use of shelters by arthropods at the experiment scale, and (ii) to predict the effects of future climate variability on refuge usage (Fig. 1). Climate data and topographic data were extracted from WorldClim (Fick and Hijmans, 2017) version 2 (http://www.worldclim.org/) and ENVIREM (Title and Bemmels, 2017) (https://envirem.github.io/). For each site we chose four variables for temperature (bio1, bio2, bio4, bio7), four variables for precipitation (bio12, bio14, bio15, Aridity), two varia- 
bles related to topography (TRI and topoWET) and one variable denoting site productivity (AnnualPET). A detailed description of the variables is presented in the Table S2. WorldClim variables were extracted at 30 arc-second, 2.5 arc-minute and 10 arc-minute resolutions. Since the above variables were very strongly correlated among these different resolutions (Pearson correlation, $\mathrm{r}[?]$ 0.97), we decided to use only data on a 10 arc-minute resolution. The variables TRI and topoWET from ENVIREM were available only for 30 arc-second resolutions. The variables Aridity and AnnualPET were extracted at 30 arc-second and 10 arc-minute resolutions; since these variables were strongly correlated between the two resolutions (Pearson correlation, $\mathrm{r}$ [?] 0.98), we used only data on 30 arc-second resolutions.

Future climate database at local scale was extracted from WorldClim version 2 using MIROC5 (RCP8.5) and CCSM4 (RCP8.5) as representative concentration pathways of $\mathrm{CO}_{2}$ emission projected for 2070 (Romero et al ., 2018). Future bioclimatic variables are not available in ENVIREM databases. Since the bioclimatic variables were very strongly correlated between these two predictive climatic models (Pearson correlation, $\mathrm{r}$ [?] 0.98), we focused our analyses only on MIROC5 (RCP8.5) database.

We measured average local temperature during the 10-day experiment. For sites missing such data, we extracted the mean near-surface daily temperature from the RNCEP database (Kemp et al., 2012). This was done for all the 10 days of the experiment, from which data we then calculated the average over the experiment. The RNCEP database has a spatial resolution of $2.5 \times 2.5^{\circ}$ and a temporal resolution of $6 \mathrm{~h}$ (Kemp et al., 2012).

\section{Statistical analyses}

\section{Effect size calculations}

Even though we have used a standardized protocol, the sampling was conducted by several researchers in different biomes. Thus, we used a meta-analysis (meta-regression) approach to control for biases in sampling (Gurevitch, 2013). The magnitude of the leaf shelter effect on arthropod community structure (measured as abundance, species richness, biomass and body size) was calculated at the site level ( $\mathrm{n}=52$ sites) using Hedges' d (standardized mean difference; Rosenberg et al ., 2013) following the formula:

Hedges $d=\frac{X e-X c}{\text { SDpooled }}$,

where $X e$ and $X c$ are the mean community measures for plants that had their leaves rolled and control plants, respectively, andSDpooled is the pooled standard deviation of the two groups. Positive effects indicate that leaf rolls had higher arthropod species abundance, richness, biomass or mean body size relative to the control leaves. Values around $0.2,0.5$ and 0.8 are considered small, medium and large effect sizes, respectively (Rosenberg et al., 2013). Larger effect size values mean larger differences in occupation of rolled compared to control leaves. Although we initially classified the surveyed arthropods into different feeding guilds (i.e., predators, herbivores, detritivores, omnivores and parasitoids), the sample size was only sufficiently large for separate analyses of predators and herbivores.

\section{Moderators (predictors)}

We investigated different categories of moderators, including absolute latitude and elevation, as well as climate, productivity (annualPET), topography (TRI, topoWET), leaf size and average temperature during the experiments. Additional local moderators included available potential prey (abundance of herbivores) for predators and abundance of predators on experimental leaves for herbivores.

To create the climate gradients, we projected separately precipitation and temperature variables in multivariate space using principal component analysis (PCA) (Romero et al ., 2018). Scores of the first axis of PCA for temperature variables $\left(\mathrm{PC}_{\text {temperature }}\right.$, which explained $78 \%$ of the total variance) represented a gradient spanning from higher temperature variability to warming and lower temperature variability. Conversely the first axis of PCA for precipitation variables $\left(\mathrm{PC} 1_{\text {precipitation}}\right.$ : $64 \%$ of the total variance) represented a rainfall (dry to wet) gradient, at global (Fig. 1) and local scales (Figs. S2-S3). PC1 precipitation included mean annual precipitation (bio12), precipitation of driest month (bio14), index of the degree of water deficit below water 
need (aridity) and precipitation seasonality (coefficient of variation) along the year (bio15) (Table S1). The only variable denoting rainfall variability (bio15) did not contribute much to the PCA1 variance (Fig. 1, Fig. S2). Therefore, the $\mathrm{PC}_{\text {precipitation }}$ represented a rainfall gradient, which varied from dry (negative values) to wet conditions (positive values) (Fig. 1, Fig. S2). Sites defined as being climatically more suitable were those characterized by higher $\mathrm{PC}_{\text {precipitation }}$ scores. $\mathrm{PC} 1_{\text {temperature included mean annual temperature }}$ (bio1), mean diurnal range (bio2), temperature seasonality (bio4) and temperature annual range (bio7). The signs of original $\mathrm{PC}_{\text {temperature }}$ scores were multiplied by -1 to change their graphic presentation for the ease of interpretation, matching with precipitation trends, thus producing a gradient from temperature variability (negative values) to warming and lower temperature variability (positive values). Sites defined as being thermally more variable were those characterized by higher intra-annual (e.g., bio4, bio7) or diurnal (e.g., bio2) variation in temperature (Fig. 1, Fig. S3).

Some moderators were collinear (Fig. S4), and were thus removed from the models based on their variance inflation factor (VIF) (Zuur et al., 2010). The removed moderators were Latitude, topoWET and AnnualPET. All remaining moderators had VIF $<2$. The best-fitting linear models were then obtained through backward selection; the best models retained were those to present the smallest Akaike Information Criteria corrected for small sample sizes, AICc ([?]AICc $>2$ ). Null models (intercept-only effects, i.e., no moderators included) were contrasted with models containing moderators plus the intercept.

\section{Meta-analysis and structural equation modelling}

We tested the effects of the moderators on Hedges' d effect sizes using meta-regression approach (linear models), conducted using metaforpackage (version 2.1-0) (Viechtbauer, 2010) implemented in R environment (R Development Core Team, 2019). Prior to the analyses, we inspected outliers through diagnostic plots (Cook's distance). We also visually inspected normality of the residuals using normal quantile-quantile ( $\mathrm{Q}^{-}$ Q) plots; our models presented appropriate behaviour in terms of residuals and outliers. Overall effect size was obtained through random-effects models, and the moderators were examined through mixed-effects models (Viechtbauer, 2010). Such mixed-effect models were obtained using a restricted maximum likelihood (REML) estimator, assuming a random variation among replicates within a treatment (control or experimental), and fixed variation among treatments. The moderator effects were estimated using Cochran's Q-test with model fitting throughmods argument to ignore the intercept and rma function (Viechtbauer, 2010). Effect sizes were considered statistically significant if their $95 \%$ confidence intervals did not overlap with 0 .

Piecewise structural equation models ( $P S E M$ ) were used to test direct and indirect effects of latitude and underlying climatic components $\left(\mathrm{PC}_{\text {temperature }}\right.$ and $\mathrm{PCI}_{\text {precipitation }}$ ) (Romero et al ., 2018) on the Hedges' $\mathrm{d}$ effect size for predators and herbivores; for this, we used the piecewiseSEM package in R (Lefcheck, 2016), and evaluated model fits using Shipley's test of d-separation through Fisher's C statistics (Lefcheck, 2016).

\section{Raw data analysis and visualisation}

Analyses of raw data were performed to graphically visualize the patterns of refuge use by predators and herbivores. For this, we built linear mixed effects models (LMEs) and evaluated the effects of treatments (control vs rolled leaves) in raw data using nlmepackage in $\mathrm{R}$ (Pinheiro et al ., 2020). Treatment was the fixed effect, and block was the random effect. We then used these LME models to generate the predictive regression trends graphically usingvisreg (Breheny and Burchett, 2017) and ggplot2 (Wickham, 2016) packages in R environment.

\section{Predicting spatial and temporal variations: maps}

We mapped the effect of future climate change on the magnitude of the effect of ecosystem engineers on arthropods using the effect sizes (Hedges' d) obtained at the experiment scale.

The magnitudes of the engineering effects on arthropod communities observed at each site and their association with climatic variables (see Table S1 for variable definitions) were tested using linear models (Gaussian error distribution). We used the function predict.lm to obtain the predicted relationship between independent variables and the Hedges' d effect size (abundance, richness and biomass) $(\mathrm{n}=52)$. Temperature (bio1, 
bio2, bio4, bio7) and precipitation (bio12, bio14, bio15) were included as independent continuous variables in separate models (see Table S1 for variable definitions). Separate climatic variables rather than the principal component scores identified in our meta-analyses were used because the correlations structure among variables may shift with climate change, and thus parameter estimation may be biased in different models (Hadi and Ling, 1998). In addition, using the climatic variables in the predictive modelling allowed us to inspect the reliability of the predict.lm function. However, for both temperature and precipitation climatic models most variables were collinear (see Figs. S2 and S3). We therefore first eliminated the influence of collinearity using the variance inflation factor (VIF) (Zuur et al., 2010). We then reduced the model through backward selection, retaining only the significant variables and those that improved the model fit (i.e., higher $\mathrm{R}^{2}$ values). We modelled the current climate scenario and those projected to 2070 using rcp8.5 (MIROC5) as a general circulation model. We checked normality, homoscedasticity and outliers through graphical inspections (e.g., qq-plots, Cook's d, and influence), and residuals of the response variables were log transformed when necessary. Previous studies have used this approach to modelling distribution maps to provide a geographical interpretation of global ecological patterns (Tallavaaraet al ., 2018, Gusmao et al ., 2020).

Model performance was tested using a $k$-fold cross-validation approach (see Appendix S1).

\section{RESULTS}

\section{Current interactions}

Overall, predators, herbivores and the pooled arthropod assemblages including all feeding guilds (predators, herbivores, detritivores, parasitoids, omnivores) were strongly influenced by the presence of leaf rolls on plants (Fig. 2). Arthropod abundance, species richness, biomass and mean body size were significantly higher in rolled compared to control leaves (i.e., positive Hedges'd values, with $95 \%$ confidence intervals not spanning 0).

The effects of leaf rolls on pooled arthropod assemblages were not significantly influenced by any moderator (Table 1). The effects of leaf rolls on predators were mediated solely by climate, but the effects of precipitation and temperature varied depending on predator metrics (abundance, richness, biomass). The magnitude of the effect of leaf rolls on predator abundance and species richness increased with drought $\left(\mathrm{PC} 1_{\text {precipitation }}\right.$, Table 1, Fig. 3). Predator abundance on plants was strongly positively correlated with predator species richness $(\mathrm{r}=0.86, \mathrm{t}=12.2, \mathrm{P}<0.001)$, and thus the effects of leaf shelters on both community metrics were similarly influenced by precipitation gradients (Table 1, Fig. 3). In contrast, the positive effects of leaf rolls on predator biomass increased with greater temperature variability, but decreased in warmer regions (Table 1, Fig. 3). Latitude did not directly influence refuge usage by arthropods, but had a positive indirect effect via temperature gradient on the increase in predator biomass in leaf shelters $\left(\mathrm{PC}_{\text {temperature }}, \beta=0.28\right.$, Fig. S5c). Predator biomass within leaf shelters and on control leaves was positively correlated with predator body size (shelter: $\mathrm{r}=0.82, \mathrm{t}=9.6, \mathrm{P}<0.001$; control: $\mathrm{r}=0.94, \mathrm{t}=16.6, \mathrm{P}<0.001$ ), but not with predator abundance (shelter: $\mathrm{r}=0.23, \mathrm{t}=1.6, \mathrm{P}=0.11$; control: $\mathrm{r}=0.14, \mathrm{t}=0.98, \mathrm{P}=0.33$ ). Thus, shelter usage, mostly by larger predators, increased toward higher latitudes, where temperature variability is higher.

In contrast to the effect of leaf rolls on predators, positive effects of leaf shelters on the magnitude of the effect on herbivore abundance and biomass were stronger in wet sites, but also on plants with a higher abundance of predators (Table 1, Fig. 3). Herbivore biomass within leaf shelters and on control leaves was strongly positively correlated with the mean body size of the individuals (shelter: $\mathrm{r}=0.88, \mathrm{t}=12.4, \mathrm{P}<0.001$; control: $\mathrm{r}=0.74, \mathrm{t}=6.7, \mathrm{P}<0.001$ ), but not with their abundance (shelter: $\mathrm{r}=0.05, \mathrm{t}=0.37, \mathrm{P}=0.71$; control: $\mathrm{r}=$ $0.13, \mathrm{t}=0.88, \mathrm{P}=0.38$ ). Average herbivore body size was $41 \%$ smaller than average predator body size (Fig. S6).

Likewise, data visualization performed using linear mixed effects modelling with raw data revealed contrasting patterns of leaf shelter usage by herbivores and predators (Fig. S7). Predator abundance, species richness and biomass increased within refuges in a drier climate and with increasingly variable temperatures. In contrast, herbivores were more likely to use shelter under wetter climates (Fig. S7). Other moderators such 
as elevation, ecosystem productivity, topography and local average temperature did not directly influence the effects of shelters on arthropods (Table 1).

\section{Future predicted interactions}

The magnitude of the effect of refuge on species richness and abundance of predators is expected to increase by up to $33 \%$ and $38 \%$, respectively, in areas where precipitation is predicted to decline (e.g., French Guiana and Mexico). In contrast, with increasing precipitation predicted for sites in Europe, USA, and Borneo, the effects of refuge on predator species richness and abundance are expected to decrease by up to $25 \%$ and $34 \%$, respectively (Fig. 4a, Fig. S8).

Future scenarios of the influence of temperature on refuge usage by larger predators depended on the temperature component evaluated (i.e., temperature variability [bio7] versus mean annual temperature [bio1]). Maps of effects for predator biomass revealed weaker changes in response to temperature variability over time, compared to responses to precipitation (Fig. 4b). Indeed, key bioclimatic variables reflecting precipitation (e.g., bio14) are predicted to be more variable over time than key temperature variables (e.g., bio7) (Appendix S2). This weak effect is manifested as smaller differences in future versus current effect sizes (ranging from a decrease of up to $2.3 \%$ and an increase of up to $6.7 \%$ ), likely stemming from the fact that temperature variability itself will change little in the future. However, under a scenario of increasing mean annual temperature, a general warming is predicted to decrease (6-17\%) the effect of shelters on larger predators, especially in Europe (Fig. S9).

\section{DISCUSSION}

Our results indicate that structural refuges provided by leaf rolls increase the local abundance, diversity, biomass and mean body size of arthropods from different trophic levels on plants, and they do so on all four continents on which the experiment was conducted. However, the pattern of refuge use by herbivores and predators in response to climate differed: while predators used refuges more with increasing drought and temperature variability, use of refuges by herbivores showed opposite trends. This suggests that herbivores might avoid the use of refuges in sites with increasing drought and temperature variability, where risk of predation is higher (Wetzel et al., 2016). Such predation risk might drive herbivores to suboptimal microhabitats in harsh conditions. Herbivorous insects are often smaller than predatory arthropods (see Fig. S6), and thus likely are less vulnerable to climatic adversities (Petchey et al., 1999; Voigt et al., 2003; Brose et al., 2012). In addition, in contrast to many predators, herbivores can build their own refuges using plants (Pincebourde and Casas, 2019) and access a more predictable source of water from food (green leaves). Predators rely on more stochastic water sources (e.g., prey haemolymph), which are dependent on prey capture rates. Conversely, larger herbivores might seek refuges against vertebrate predators under more stable and favourable climatic conditions (Tvardikova and Novotny, 2012), where predation pressure on larger herbivores is often high (Romero et al ., 2018). It is therefore likely that herbivores use leaf shelters more as a refuge against natural enemies (Baer and Marquis, 2020) than for protection against harsh climatic conditions.

Climate variability and drought appear to be the key determinants of refuge use, especially by predatory arthropods. However, different metrics of predator communities (abundance, species richness, biomass) were differentially influenced by components of precipitation and temperature. It is likely that drought may shape species composition within leaf shelters, as the refuges tend to be occupied by species sensitive to desiccation. Indeed, predatory arthropod taxa have varying susceptibility to desiccation (Edney, 2012); leaf shelters could provide them with humidity via leaf transpiration, and offer stable microclimatic refuges against long droughts. However, we found refuge usage to be higher for larger predators. As larger predators show a smaller surface-to-volume ratio than small ones (Kühselet al ., 2017), they are likely less prone to desiccation. Despite being less vulnerable to desiccation, larger predators can be competitively dominant over smaller ones in using available refuges.

Our results also reveal that larger predators were most influenced by temperature variability. This effect is likely mediated by large predators being subject to the stronger physiological constraints imposed by tempe- 
rature and/or having the strongest competitive ability under such climatic conditions. In fact, temperature variability imposes greater risks to arthropods than warming (Vasseur et al ., 2014; Colinet et al., 2015), especially for species from higher trophic levels (Stireman et al ., 2005). Refuges might ameliorate temperature oscillations and heat waves (Caillon et al., 2014), which are harmful especially to larger organisms, such as predators (Voigt et al., 2003; Brose et al., 2012; Horne et al ., 2017). It is known that heat transfer (or dissipation) is reduced in larger organisms because of their smaller surface area-to-volume ratios (Horne et al ., 2017), causing a threat in more thermally variable climates. Due to their higher competitive ability, large predators in particular may thus rely on refuges against extreme temperature oscillations, despite being less vulnerable to desiccation (Kühsel et al., 2017).

The climatic variables that we considered consist of both annual means and variances, thus characterizing the overall climatic conditions of each site. We found that increasing variability in climate, and not changes in the mean of the climate variable, was positively correlated with predator response to shelter availability. If communities of predators experience higher climatic variability during at least some part of the year over time, then shelter use in general may be favoured by selection. This hypothesis is supported by the fact that the climatic variable spanning the duration of the experiment itself (average temperature over 10 days) did not moderate the influence of leaf shelters on predators. Predators (e.g., spiders) are well known to actively select sheltered microhabitats in harsh conditions and fire-prone environments (de Omena and Romero, 2010). Therefore, we suggest that the behaviour of using leaf shelters might be an evolutionary response to drought and climatic variability.

Arthropods comprise over two-thirds of all terrestrial species, and are key elements in intricate food webs. They provide valuable ecosystem services, such as biological control, nutrient cycling and pollination. Because arthropods are ectothermic and closely dependent on external energy, they are also among the most threatened organisms on Earth due to ongoing global changes (van Klink et al ., 2020; Wagner, 2020, Wagner et al. 2021). With increase in climate variability and in frequency of extreme droughts, terrestrial arthropod communities should be more dependent on suitable microclimate (Pinsky et al ., 2019), with body size and trophic position having a major influence on microhabitat use. Understanding how arthropods deal with climate oscillations and extremes is thus pivotal for improved conservation and mitigation strategies. Efficient strategies should aim at identifying and preserving local conditions, such as habitat structural components, to buffer climatic adversities. Here, we present clear evidence that refuges provided by ecosystem engineers may mitigate predicted increases in climate variability and drought. As a direct projection from the patterns observed, we predict that future changes in climatic conditions could change the global pattern of refuge use by arthropods. In the future, ecosystem engineers are expected to increase in importance, especially for predators and in sites where rainfall is expected to decrease. Increased future usage of shelters by predators might then strongly alter predation risk on herbivores, and even strengthen intraguild predation pressure upon plants.

Our results point to larger predators as the dominant organisms using refuges. This dominance likely results from higher competitive dominance and/or higher sensitivity to global changes. The refuges can mitigate climatic variation, allowing predators to adjust their use of niche space according to their physiological tolerances. The ability to forage from such refuges may still have a strong effect on their overall performance, and on the overall imprint of climate on arthropod community change. Increasing climatic variability and drought may decrease the ability of such predators to feed and thus to perform important ecosystem services (Barton and Schmitz, 2009; Rosenblatt and Schmitz, 2016) such as biological control. Likewise, increasing refuge usage by predators with climate change could displace herbivores to suboptimal microclimates (Barton and Schmitz, 2009). Asymmetric reliance on refuge use by predator and prey, and mismatches in predatorprey encounter rates, could cause asymmetric extinctions of larger herbivores and predators (Clark et al., 2020). While the realism of these scenarios remains to be seen, current patterns of climatic impacts on refuge use and their extensions into the future flag a potential ecosystem transition. Importantly, they identify a minuscule scale in microclimatic research as an important avenue for future research on ecosystem functioning and community ecology. 


\section{ACKNOWLEDGMENTS}

We acknowledge financial support for research provided by the Sao Paulo Research Foundation (FAPESP: grants 2017/09052-4, 2018/12225-0, and BPE Proc. 2016/01209-9) and CNPq-Brazil through research grants to GQR. GQR and PK gratefully acknowledge funding from the Royal Society, Newton Advanced Fellowship (grant no. NAF/R2/180791). TR was supported by the Academy of Finland (grant 322266) and a senior career support grant from the Vice Chancellor of the Swedish University of Agricultural Sciences. RJM thanks the Missouri Department of Natural Resources for access to Cuivre River State Park, Zhaid Khaja for help in the field, and the Students and Teachers as Research Scientists (STARS) program for financial support. NACM acknowledges CAPES for a post-doctoral research grant (PNPD/CAPES \#2013/0877), VN acknowledges the CSF 20-10205S and ERC 669609 grants. TC acknowledges CNPq (307210/2016-2) and CAPES. JO acknowledges access to the Paracou research station in French Guiana, which is supported by CIRAD (https://paracou.cirad.fr/) and financial support provided by an Investissement d'Avenir grant of the Agence Nationale de la Recherche (CEBA, ANR-10-LABX-25-01) and by the PO-FEDER 2014-2020, Région Guyane (BiNG, GY0007194). WD and RA are grateful to Rosamond Coates and all the staff of the Estación de Biología Tropical Los Tuxtlas (Universidad Nacional Autónoma de México), besides the staff of the Santuario del Bosque de Niebla and Centro de Investigaciones costeras La Mancha (Instituto de Ecología A.C.) who have made the fieldwork possible. HG was supported by an Australian Research Council Future Fellowship (FT130100821). TJI is supported by CNPQ (grants 309552/2018-4). TK was supported by the Czech University of Life Sciences Prague (grant no. 42900/1312/3166). VK acknowledges funding from grant NE/K016148/1/Natural Environment Research Council. MK was supported by the Czech University of Life Sciences Prague (grant no. 42900/1312/3166). RM acknowledges Tswalu Kalahari for permission to conduct fieldwork and Bryan Maritz and Graham Alexander for help in the field. PMM acknowledges the Dunedin Botanic Garden's administration for allowing data collection, and thank Penelope Jacks and Esther Dale for their valuable support during different stages of the fieldwork. EM acknowledges Tamiru Shimales. JM was supported by the Slovak national grant VEGA2/0100/18. AM acknowledges the GAJU n. 04-048/2019/P grant. CCP acknowledges CAPES (financial code 001). MSP and SM thank the Nature Park Medvednica and Ministry of Environment and Energy of the Republic of Croatia for allowing access to the Croatian study

sites. SPR thank CNPq (306572/2019-2). MKT acknowledges Danielle Courcelles for assistance in field work. CV was supported by Coordenação de Aperfeiçoamento de Pessoal de Nível Superior (CAPES) Proc. 88882.314749/2019-01. EG was supported by the Czech University of Life Sciences Prague (grant no. 42900/1312/3166). MQ was supported by grants from Universidad Nacional Autónoma de México (PAPIIT IV200418), SADER-CONACYT 291333, CONACYT-UNAM to LANASE (2019-LN299033); MQ thank Gumersindo Sanchez for help in the field. TT was supported by the Estonian Research Council (grant no. PRG741), and by the Internal Grant Agency of the Faculty of Environmental Sciences, Czech University of Life Sciences Prague (grant no. 42900/1312/3166). M-LV was supported by the Estonian Research Council (grant no. PRG741).

\section{REFERENCES}

Baer, C.S. \& Marquis, R.J. (2020). Between predators and parasitoids: complex interactions among shelter traits, predation and parasitism in a shelter-building caterpillar community. Functional Ecology , 34, 21862198.

Barton, B.T \& Schmitz, O.J. (2009). Experimental warming transforms multiple predator effects in a grassland food web. Ecology Letters , 12, 1317-1325.

Bathiany, S., Dakos, V., Scheffer, M. \&Lenton, T.M. (2018). Climate models predict increasing temperature variability in poor countries.Science Advances , 4, eaar5809.

Breheny, P. \& and Burchett, W. (2017). Visualization of regression models using visreg. The R Journal , 9, 56-71. 
Brose, U., Dunne, J.A., Montoya, J.M., Petchey, O.L., Schneider, F.D. \& Jacob, U. (2012). Climate change in size-structured ecosystems.Philosophical Transactions of the Royal Society B , 367, 2903-2912.

Caillon, R., Suppo, C., Casas, J., Woods, H.A. \& Pincebourde, S. (2014). Warming decreases thermal heterogeneity of leaf surfaces: implications for behavioural thermoregulation by arthropods.Functional Ecology , 28, 1449-1458.

Clark, J.S., Scher, C.L. \& Swift, M. (2020). The emergent interactions that govern biodiversity change. PNAS , 117, 17074-17083.

Colinet, H., Sinclair, B.J., Vernon, P. \& Renault, D. (2015). Insects in fluctuating thermal environments. Annual Review of Entomology, 60, 123-140.

Cornelissen, T., Cintra, F. \& Santos, J.C. (2015). Shelter-building insects and their role as ecosystem engineers. Neotrop. Entomol ., 45, 1-12.

Daufresne, M., Lengfellner, K. \& Sommer, U. (2009). Global warming benefits the small in aquatic ecosystems. Proc. Natl Acad. Sci. USA , 106, 12788-12793.

de Omena, P.M. \& Romero, G.Q. (2010). Using visual cues of microhabitat traits to find home: the case study of a bromeliad-living jumping spider (Salticidae). Behavioral Ecology , 21, 690-695.

Donat, M. G., Lowry, A. L., Alexander, L. V., O'Gorman, P. A. \& Maher, N. (2016). More extreme precipitation in the world's dry and wet regions. Nat. Clim. Change, 6, 508-513.

Edney, E.B. (2012). Water balance in land arthropods. Springer-Verlag, Berlin.

Essl, F., Dullinger, S., Genovesi, P. ... Bacher, S. (2019). A Conceptual Framework for range-expanding species that track human-induced environmental change. BioScience, 69, 908-919.

Fick, S. E. \& Hijmans, R. J. (2017). WorldClim 2: new 1-km spatial resolution climate surfaces for global land areas. Int. J. Climatol ., 37, 4302-4315.

Fitzgerald, T.D., Clark, K.L., Vanderpool, R. \& Phillips, C. (1991). Leaf shelter-building caterpillars harness forces generated by axial retraction of stretched and wetted silk. Journal of Insect Behavior , 4, 21-32.

Fukui, A. (2001). Indirect interactions mediated by leaf shelters in animal-plant communities. Population Ecology , 43, 31-40.

Garcia-Robledo, C., Erin K. Kuprewicz, E.,K., Staines, C.L., Erwin, T.L. \& Kress, W.J. (2016). Limited tolerance by insects to high temperatures across tropical elevational gradients and the implications of global warming for extinction. PNAS, 113, 680-685.

Gurevitch, J. (2013). Meta-analysis of results from multisite studies. In Koricheva, J., Gurevitch, J. \& Mengersen, K. (eds.). Handbook of meta-analysis in ecology and evolution. Princeton University Press, Princeton and Oxford.

Gusmao, R.A.F., Hernandes, F.A., Vancine, M.H., Naka, L.N., Dona, J., Goncalves-Souza, T. (2020). Host diversity outperforms climate as a global driver of symbiont diversity in the bird-feather mite system. Diversity and Distributions https://doi.org/10.1111/ddi.13201

Hadi, A.S. \& Ling, R.F. (1998). Some cautionary notes on the use of Principal Components Regression. The American Statistician, 52, 15-19.

Hastings, A., Byers, J. E., Crooks, J. A., Cuddington, K., Jones, C. G., Lambrinos, J. G., Talley, T. S. \& Wilson, W.G. (2007). Ecosystem engineers in space and time. Ecology Letters, 10, 153-164.

He, Q., Bertness, M.D, Altieri, A.H. (2013). Global shifts towards positive species interactions with increasing environmental stress. Ecology Letters , 16, 695-706. 
Hodar, J.A. (1996). The use of regression equations for estimation of arthropod biomass in ecological studies. Acta Oecologica , 17, 421-433.

Horne, C.R., Hirst, A.G. \& Atkinson, D. (2017). Seasonal body size reductions with warming covary with major body size gradients in arthropod species. Proc. R. Soc. B. , 284, 20170238.

IPCC Climate Change 2014: Synthesis Report (eds Core Writing Team, Pachauri, R. K. \& Meyer, L. A.).

Jones, C.G., Lawton, J.H., Shachak, M. (1997). Positive and negative effects of organisms as physical ecosystem engineers. Ecology,78, 1946-1957.

Kemp, M.U., van Loon, E.E., Shamoun-Baranes, J. \& Bouten, W. (2012). RNCEP: global weather and climate data at your fingertips. Methods in Ecology and Evolution, 3, 65-70. (2012).

Kuhsel, S., Bruckner, A., Schmelzle, S., Heethoff, M. \& Bluthgen, N. (2017). Surface area-volume ratios in insects. Insect Science, 24, 829-841.

LaManna, J. A. et al. (2017). Plant diversity increases with the strength of negative density dependence at the global scale.Science, 356, 1389-1392.

Lefcheck, J. S. (2016). piecewiseSEM: piecewise structural equation modelling in R for ecology, evolution, and systematics. Methods Ecol. Evol ., 7, 573-579.

Lill, J.T., Marquis, R.J. (2007). Microhabitat manipulation: ecosystem engineering by shelter-building insects. In: K. M. D. Cuddington, J. E. Byers, A. Hastings, and W. G. Wilson (eds.), Ecosystem engineers: concepts, theory, and applications in ecology, pp. 107- 138, Elsevier Press. San Diego, CA.

Petchey, O.L., McPhearson, P.T., Casey, T.M. \& Morin, P.J. (1999). Environmental warming alters food-web structure and ecosystem function.Nature , 402, 69-72.

Pincebourde, S. \& Casas, J. (2019). Narrow safety margin in the phyllosphere during thermal extremes. PNAS , 116, 5588-5596.

Pinheiro J., Bates D., DebRoy S., Sarkar D., R Core Team. (2020). nlme: Linear and Nonlinear Mixed Effects Models. R package version 3.1-148.

Pinsky, M.L., Eikeset, A.M., McCauley, D.J., Payne, J.L. \& Sunday, J.M. (2019). Greater vulnerability to warming of marine versus terrestrial ectotherms. Nature , 569, 108-111.

Priest, G.V., Cameroata, F., Powell, S., Vasconcelos, H.L., Marquis, R.J. (2021). Ecosystem engineering in the arboreal realm: Heterogeneity of wood-boring beetle cavities and their use by cavity-nesting ants. Oecologia (in press).

R Development Core Team (2019). R: A Language and Environment for Statistical Computing (R Foundation for Statistical Computing).

Romero, G.Q. \& Koricheva, J. (2011). Contrasting cascade effects of carnivores on plant fitness: a metaanalysis. J. Anim. Ecol ., 80, 696-704.

Romero, G.Q., Goncalves-Souza, T., Kratina, P., Marino, N.A.C, Petry, W.K., Sobral-Souza, T. \& Roslin, T. (2018). Global predation pressure redistribution under future climate change. Nature Climate Change, 8, 1087-1091.

Romero, G.Q., Goncalves-Souza, T., Vieira, C., Koricheva, J. (2015). Ecosystem engineering effects on species diversity across ecosystems: a meta-analysis. Biological Reviews , 90, 877-890.

Rosenberg, M.S., Rothstein, H.R. \& Gurevitch, J. (2013). Effect sizes: conventional choices and calculations. In Koricheva, J., Gurevitch, J. \& Mengersen, K. (eds.). Handbook of meta-analysis in ecology and evolution. Princeton University Press, Princeton and Oxford. 
Rosenblatt, A. E. \& Schmitz, O. J. (2016). Climate change, nutrition, and bottom-up and top-down food web processes. Trends Ecol. Evol ., 31, 965-975.

Roslin, T. et al. (2017). Higher predation risk for insect prey at low latitudes and elevations. Science, 356, $742-744$.

Rubalcaba, J.G., Gouveia, S.F., Olalla-Tarraga, M.A. (2019). A mechanistic model to scale up biophysical processes into geographical size gradients in ectotherms. Global Ecology and Biogeography , 28, 793-803.

Scheffers, B.R. Edwards, D.P., Diesmos, A., Williams, A.E \& Evans, T.A. (2014). Microhabitats reduce animal's exposure to climate extremes. Global Change Biology , 20, 495-503.

Schemske, D. W. et al. (2009). Is there a latitudinal gradient in the importance of biotic interactions? Annu. Rev. Ecol. Evol. Syst ., 40, 245-269.

Stireman III, J.O., L.A. Dyer, D.H. Janzen, M.S. Singer, J.T. Lill, R.J. Marquis, R.E. Ricklefs, G.L. Gentry, W. Hallwachs, P.D. Coley, J.A. Barone, H.F. Greeney, H. Connahs, P. Barbosa, H.C. Morais, and I.R. Diniz. (2005). Climatic unpredictability and parasitism of caterpillars: Implications of global warming. PNAS , 102, 17384-17387.

Suggitt, A.J., Wilson, R.J., Isaac, N.J.B. et al. (2018). Extinction risk from climate change is reduced by microclimatic buffering. Nature Clim Change, 8, 713-717.

Tallavaara, M., Eronen, J.T. \& Luoto, M. (2018). Productivity, biodiversity, and pathogens influence the global hunter-gatherer population density. Proc Natl Acad Sci USA , 115, 1232-1237.

Title, P. O. \& Bemmels, J. B. (2017). ENVIREM: an expanded set of bioclimatic and topographic variables increases flexibility and improves performance of ecological niche modeling. Ecography , 41, 291-307.

Trisos, C.H., Merow, C. \& Pigot, A.L. (2020). The projected timing of abrupt ecological disruption from climate change. Nature, 580, 496-501.

Tvardikova, K. \& Novotny, V. (2012). Predation on exposed and leaf-rolling artificial caterpillars in tropical forests of Papua New Guinea. Journal of Tropical Ecology , 28, 331-341.

van Klink, R., Bowler, D.E., Gongalsky, K.B., .. Chase, J.M. (2020). Meta-analysis reveals declines in terrestrial but increases in freshwater insect abundances. Science, 368, 417-420.

Vasseur, D. A. et al. (2014). Increased temperature variation poses a greater risk to species than climate warming. Proc. R. Soc. B , 281, 20132612.

Vazquez, D.P., Gianoli, E., Morris, W.F., \& Bozinovic, F. (2017). Ecological and evolutionary impacts of changing climatic variability.Biological Reviews , 92, 22-42.

Viechtbauer, W. (2010). Conducting meta-analyses in R with the metafor package. Journal of Statistical Software, 36, 1-48.

Vieira, C. \& Romero, G.Q. (2013). Ecosystem engineers on plants: indirect facilitation of arthropod communities by leaf-rollers at different scales. Ecology , 94, 1510-1518.

Voigt W., Perner J., Davis A.J., Eggers T., Schumacher, J., Bahrmann R., Fabian B., Heinrich W., Kohler G., Lichter D., Marstaller R. \& Sander F.W. (2003). Trophic levels are differentially sensitive to climate.Ecology , 84, 2444-2453.

Wagner, D.L. (2020). Insect declines in the Anthropocene. Annual Review of Entomology , 65, 457-480.

Wagner, D.L., Grames, E.M., Forister, M.L., Berenbaum, M.R., Stopak, D. (2021). Insect decline in the Anthropocene: Death by a thousand cuts.PNAS 118 e2023989118.

Wang, H.G. Marquis, R.J., Baer, C.S. (2012). Both host plant and ecosystem engineer identity influence leaf-tie impacts on the arthropod community of Quercus. Ecology, 93, 2186-2197. 
Warren, R., Price, J., Graham, E., Forstenhaeusler, N. \& VanDerWal, J. (2018). The projected effect on insects, vertebrates, and plants of limiting global warming to $1.5 \mathrm{degC}$ rather than $2 \mathrm{degC}$. Science, 360, 791-795.

Wetzel, W.C., Screen, R.M., Li, I. .. \& \& Yang, L.H. (2016). Ecosystem engineering by a gall-forming wasp indirectly suppresses diversity and density of herbivores on oak trees. Ecology , 97, 427-438.

Wickham, H. (2016). ggplot2: elegant graphics for data analysis. Springer-Verlag New York.

Zuur, A.F., Ieno, E.N., Elphick, C.S. (2010). A protocol for data exploration to avoid common statistical problems. Methods in Ecology and Evolution, 1, 3-14.

\section{SUPPORTING INFORMATION}

Additional supporting information may be found online in the Supporting Information section at the end of the article.

\section{Hosted file}

Figures.pdf available at https://authorea.com/users/392513/articles/506381-climatevariability-and-drought-modulate-the-role-of-structural-refuges-for-arthropods-a-globalexperiment 